\title{
Research
}

\section{Palliative care or end-of-life care in advanced chronic obstructive pulmonary disease}

\author{
A prospective community survey
}

\begin{abstract}
\section{Background}

Calls for better end-of-life care for advanced chronic obstructive pulmonary disease (COPD) reflect the large number who die from the disease and their considerable unmet needs.

\section{Aim}

To determine palliative care needs in advanced COPD

\section{Design}

Cross-sectional interview study in patients

homes using structured questionnaires generated from 44 south London general practices.
\end{abstract}

\section{Method}

One hundred and sixty-three (61\% response) patients were interviewed, mean age 72 years, $50 \%$ female, with diagnosis of COPD and at least two of: forced expiratory volume in the first second $\left(\mathrm{FEV}_{\mathrm{V}}\right)<40 \%$ predicted, hospital admissions or acute severe exacerbations with COPD, long-term oxygen therapy, cor pulmonale, use of oral steroids, and being housebound. Patients with advanced cancer, severe alcohol-related or mental health problems, or learning difficulties, were excluded 145 patients were included in the analysis.

\section{Results}

One hundred and twenty-eight (88\%) participants reported shortness of breath most days/every day, $45 \%$ were housebound, $75 \%$ had a carer. Medical records indicated that participants were at least as severe as nonparticipants. Eighty-two (57\%) had severe breathlessness; 134 (92\%) said breathlessness was their most important problem; 31 (21\%) were on suboptimal treatment; $42(30 \%)$ who were severely affected had not been admitted to hospital in the previous 2 years; 86 of 102 who had been admitted would want admission again if unwell to the same extent. None expressed existential concerns and few discussed need in terms of end-of-life care, despite severe breathlessness and impairment.

\section{Conclusion}

Needs in advanced COPD were considerable, with many reporting severe intractable breathlessness. Palliation of breathlessness was a priority, but discussion of need was seldom in terms of 'end-of-life care'.

\section{Keywords}

COPD; dyspnoea; epidemiology; palliative care primary health care.

\section{INTRODUCTION}

Thirty thousand people die from chronic obstructive pulmonary disease (COPD) each year in the UK, almost as many as die from lung cancer, and with health and social care needs that may be at least as great.1,2 Uncontrolled symptoms, including breathlessness, cough, fatigue, anorexia, anxiety, depression, and pain are widely experienced. ${ }^{3}$ At least one-third of patients who die from COPD have had little contact with services in the year before their death. ${ }^{3}$ Studies suggesting that advanced COPD patients have palliative care needs have been limited by being unrepresentative, or by being purely qualitative, or by relying on retrospective proxy accounts. ${ }^{1-5}$ They have led to increasing calls for the palliative care of patients with advanced COPD. ${ }^{6-9}$ Despite growing interest, palliative care needs in COPD have not been described, nor has their prevalence been measured prospectively. There is no reliable guidance for generalists or specialists on how COPD sufferers who may have palliative care needs should be identified or how such needs should be discussed. Added to this has been the uncertainty about prognosis in advanced COPD. There is no evidence to support the making of a prognosis of less than 2 years in individuals with advanced COPD, irrespective of respiratory disease severity. ${ }^{10-12}$

According to the World Health Organization, palliative care is:

P White, MRCP, FRCGP, MD, senior lecturer: S White, BA, MSc, research assistant; P Seed MSc, CStat, CSci, lecturer in medical statistics, Department of General Practice and Primary Care; $\mathbf{P}$ Edmonds, FRCP, consultant and honorary senior lecturer; M Gysels, MA, PhD, senior research fellow, Department of Palliative Care and Policy; J Moxham, MD, FRCP, MD, professor of respiratory medicine, Division of Asthma and Allergy and Lung Biology; C Shipman, BA, MSc, senior research fellow, Department of General Practice and Primary Care and Department of Palliative Care and Policy, King's College London. an approach that improves the quality of life of patients and their families facing the problems associated with life-threatening illness, through the prevention and relief of suffering by means of early identification and impeccable assessment and treatment of pain and other problems, physical, psychosocial and spiritual. ${ }^{13}$

Palliative care and end-of-life care are terms that are often used interchangeably, but this can generate a confusion that conceals differences in needs and priorities. ${ }^{14}$ In designing this study of palliative care needs, the definitions and approaches developed by Higginson et al for the conceptualisation of needs have been used. ${ }^{15}$ The study has sought to identify patients in the care of UK GPs, who have advanced COPD and palliative care needs, and to define those needs.

\section{METHOD}

A cross-sectional interview study was conducted between January and October 2007 in people with advanced COPD, to determine the proportion of patients with palliative care needs and to describe their needs.

Palliative care needs were defined as having: uncontrolled severe symptoms in COPD despite optimal treatment of the disease; information needs about the risk of death, about prognosis, and about the

\section{Address for correspondence}

Patrick White, King's College London, Department of Primary Care and Public Health Sciences, 9th Floor Capital House, Weston Street, London, SE1 3QD. E-mail: patrick.whiteakcl.ac.uk Submitted: 18 June 2009; Editor's response: 8 February 2010; final acceptance: 7 September 2010

CBritish Journal of General Practice

This is the full-length article (published online 31 May 2011) of an abridged version published in print. Cite this article as: Br J Gen Pract 2011; DOI: 10.3399/bjgp11X578043. 


\section{How this fits in}

Increasing calls for better end-of-life care for patients with advanced chronic obstructive pulmonary disease (COPD) reflect the large numbers of people who die from the disease and their considerable unmet needs. Care of advanced COPD is complex, not least because prognosis is uncertain. This research has assessed the nature and prevalence of palliative care needs in patients with advanced COPD in primary care. Contrary to assumptions that have been made for this group of patients, few report end-of-life care needs, and in most the palliation of breathlessness is their main concern.

availability of treatment to control symptoms; and a need for choice about place and priorities of future treatment in the event of worsening disease.

\section{Subjects}

Eligible subjects were patients in the care of GPs, with a diagnosis of COPD and at least two of the following: forced expiratory volume in the first second $\left(F E V_{1}\right)<40 \%$ of predicted $;{ }^{16}$ hospital admission for COPD or acute exacerbation of COPD in the previous 12 months; long-term oxygen therapy (LTOT); cor pulmonale; use of oral steroids; and being housebound. Patients with advanced cancer, severe alcohol-related or mental health problems, or learning difficulties were excluded. Subjects had to have an $\mathrm{FEV}_{1}$ of less than $40 \%$ predicted according to locally validated prediction equations if their body mass index (BMI) was $\leq 30 \mathrm{~kg} / \mathrm{m}^{2}, 17$ or an $\mathrm{FEV}_{1}$ less than $30 \%$ of expected with a $\mathrm{BMI} \geq 30 \mathrm{~kg} / \mathrm{m}^{2}$, or an $\mathrm{FEV}_{1} /$ height $^{2} \leq 0.3 .17,{ }^{18}$ The threshold of FEV $<40 \%$ was used because the majority of subjects were over 70 years, and prediction equations for spirometry values in this age group are less reliable.

\section{Setting}

The study took place in the London Boroughs of Lambeth and Southwark. Lambeth was the 19th most deprived of 354 boroughs in England and Wales, and Southwark was the 26th. ${ }^{19}$ Patients were identified from GPs COPD and oxygen registers. Practices were recruited by a local GP and accepted secondment of a researcher to identify patients from the medical records, and to send letters to patients on their behalf.

\section{Development of measures}

A purpose-designed questionnaire of palliative care needs was devised in a qualitative pilot study with 20 patients. ${ }^{20}$ The topic guide for the qualitative interview study was based on a review of the literature including a retrospective survey of 209 patients who died from COPD. ${ }^{3}$ Patients were interviewed to identify their most pressing needs for health and social care with respect to symptoms, information, and choice about place of care. The interview data in the earlier qualitative study were analysed using the framework approach to explore, compare, and contrast key themes. ${ }^{21,22}$ The final questionnaire reflecting patients' needs was piloted in 10 patients. It is available online. The questionnaire content is summarised in Box 1, included the Medical Research Council (MRC) Dyspnoea Scale, pain questions from the Aberdeen, London and Leeds Pain Survey, the Eastern Co-operative Oncology Group (ECOG) performance status measure, questions on dignity drawing on the work of Chochinov et al. ${ }^{23-25}$ Questions were mainly closed in style using Likert scales for graded responses, but open questions were used to expand responses or to record new issues. Additional measures included the Hospital Anxiety and Depression Scale (HADS), and the Clinical COPD Questionnaire. ${ }^{26,27}$

Breathlessness has been described as the most important symptom in COPD.,34 To identify the most severely affected patients, a composite severe breathlessness variable was developed, amalgamating the fivepoint ('not at all' to 'every day') breathlessness frequency variable with the severity dimensions of 'breathlessness unrelieved by treatment', 'breathlessness needing more help', and 'breathlessness sitting or talking', from three other breathlessness variables in the questionnaire. Predictors of severe breathlessness were sought in demographic characteristics, other symptoms, impact on daily living, and use of drugs and services.

General and specific prompts were offered to ensure several opportunities were given to discuss information needs in COPD including information about current breathing problems, medicines, the future, symptom control, disease progression, people who might help, who to contact, what would be desired in another acute exacerbation, what to expect, and the desired style of information. Information questions avoided suggesting specific information goals or categories. Subjects were not asked whether they had discussed prognosis specifically or whether a 


\section{Box 1. Content of the interview-administered questionnaire ${ }^{a}$}

- Symptoms: breathlessness, including Medical Research Council (MRC) Dyspnoea Scale, cough, pain (questions derived from the Aberdeen, London and Leeds Pain Survey), tiredness, loss of appetite, sleeplessness, low mood, anxiety. ,1,22 $^{21}$

- Medications

- Comorbidity

- Information (source, range, quality)

- Managing

inside home lactivities of daily living)

outside home (scope of travel, contacts, transport)

- Informal carers

- Eastern Cooperative Oncology Group (ECOG) performance status measure ${ }^{24}$

- Contact with healthcare services primary care

hospital and pulmonary rehabilitation

- Acute exacerbations

- Dignity

- Spiritual understanding

- Sociodemographic characteristic

${ }^{a}$ The qestionnaire can be viewed at: http://tiny.cc/copd but no other information would be given to their GPs without their permission. The semi-structured questionnaire was followed by the measurement of height, weight, BMI, and spirometry using the Microlab electronic spirometer (Micromedical Ltd, Chatham, UK). Spirometry was conducted according to the (American Thoracic Society/European Respiratory Society [ATS/ERS] guidelines). ${ }^{30}$ Interviews were tape-recorded and the answers to open questions were transcribed. Index of Multiple deprivation (IMD) scores for patients' postcodes were obtained from the UK Government Department for Communities and Local Government. ${ }^{31}$

\section{Analysis}

Association was sought between categories of breathlessness and the other categorical variables using the $\chi^{2}$ test, and between symptom categories and continuous variables (for example, age, lung function) using tests of correlation (Spearman's rho). Optimal treatment was defined from the Global Initiative for Obstructive Lung Disease (GOLD) guidelines. ${ }^{32}$

The use of inhaled long-acting bronchodilators (beta-agonist or anticholinergic) in combination with inhaled steroids was considered to be indicated in a confirmed diagnosis of COPD if the FEV 1 was less than 50\% of predicted. The sensitivity and specificity of predictors of severe breathlessness were defined using receiving operator characteristic curves (ROC). ROC curves are the standard tool for assessing the predictive accuracy of a model or test. They plot the sensitivity of a test (rate of true positives) against 1 specificity (rate of false positives). Answers to open questions were recorded verbatim in the database and hand-searched for evidence of existential concerns, end-of-life care concerns, knowledge or beliefs about prognosis, future care, future plans, and sharing of those plans with professionals, family, or friends.

\section{RESULTS}

Forty-four of 55 (80\%) practices approached took part Imean list size 7715 patients; standard deviation 3983; range 1679-23 685). Participating practices were larger than non-participating practices, but there were no differences between them in the prevalence of diagnosed COPD 10.97 versus 0.91: $t=0.86 ; P=0.48)$, or in the points earned for quality of care $(0.98$ versus 0.91: $t=2.5 ; P=0.09) .{ }^{28}$ Two hundred and eighty-nine eligible patients were identified; 


\section{Table 1. Characteristics of participating patients with advanced}

COPD ( $n=145$ )

Characteristics

Male

Age, years

Mean, (SD; range)

$\leq 60$

$61-70$

$71-80$

$\geq 81$

\section{Marital status}

Married/living with partner

Divorced/separated

Widowed

Single

Number in the household

1

$\geq 3$

Ethnicity

White

All black groups

Indian

Other

Employment activity

Retired

Unable to work (due to illness)

In paid work

Full-time working at home (looking after dependants)

Ever in paid employment or self-employed

Last job

Manager

Foreman/supervisor

Employee

Self-employed

Not applicable

Education

Education after 16 years

University degree or equivalent

Smoking

Ever smoked

Smoker at time of interview

Living arrangements

Own home

Rented home

Home of relative

Other

Index of multiple deprivation (IMD)

Mean (SD; range)

Mean IMD for Lambeth and Southwark (SD; range)

Cared for now due to illness/disability or old age

Yes, by person in the household

Yes, by person not in the household

Lung function

Mean percentage of predicted FEV 1

(SD; range; $95 \% \mathrm{Cl}$ )

Mean $\mathrm{FEV}_{1} / \mathrm{FVC}$

(SD; Range; $95 \% \mathrm{Cl}$ )

FEV1 = forced expiratory volume in first second. FVC = forced vital capacity. IMD = Index of Multiple Deprivation $S D=$ standard deviation. ${ }^{a}$ National mean IMD in 2007 was 21.6; the higher the IMD the greater the deprivation. SSubject with \% expected of $78 \%$ was aged 93 years, with FEV1 of 0.7 l, FEV1/height2 $=0.33$. cFive subjects with FEV1/FVC $>0.7$ had FEV1 less than 0.87 ( $(4<0.53$ l), and none could sustain forced expiration due to frailty.

24 were ineligible because of inadequate English ( $n=3$ ), exclusion criteria reported later by the GP ( $n=7)$, admission to hospital $\boldsymbol{n}(\%)$, unless otherwise stated

73 (50.3)

$71.63(9.7 ; 32-93)$

$23(15.9)$

32 (22.1)

$67(46.2)$

23 (15.9)

54 (37.2)

20 (13.8)

$48(33.1)$

23 (15.9)

68 (46.9)

$60(41.4)$

$16(11)$

134 (92.4)

8 (5.6)

$2(1.4)$

$1(0.7)$

$116(80)$

$17(11.7)$

4 (2.8)

8 (5.5)

135 (93.1)

$13(9)$

$11(7.6)$

97 (66.9)

$16(11)$

$7(4.8)$

14 (9.7)

9 (6.2)

140 (97)

50 (34.5)

30 (20.7)

$105(72.4$

$2(1.4)$

$6(4.1)$

36.7(9.7-59)

34.1(7.1-59)

65 (44.8) 43 (29.7)

29.1 0.4

(0.11; $0.15-0.76$; 0.22 to 0.58 )
IMD the greater the deprivation.
height2 $=0.33$. cFive subjects with
rced expiration due to frailty.

( $n=1)$, death before contact $(n=6)$, and death before interview ( $n=7)$. One hundred and sixty-three $(61.5 \%)$ of the remaining 265 


\begin{tabular}{|c|c|}
\hline COPD symptoms & $n(\%)$ \\
\hline \multicolumn{2}{|l|}{ Breathlessness frequency } \\
\hline On several days or fewer & 15 (10.3) \\
\hline On most days & $16(11.0)$ \\
\hline Every day & $111(76.6)$ \\
\hline Only with a chest infection & $3(2.1)$ \\
\hline Severe breathlessness ${ }^{a}$ & $63(43.4)$ \\
\hline \multicolumn{2}{|l|}{ Cough } \\
\hline On several days or fewer & $36(24.8)$ \\
\hline On most days & $17(11.7)$ \\
\hline Every day & $74(51.0)$ \\
\hline Only with a chest infection & $18(12.4)$ \\
\hline \multicolumn{2}{|c|}{ Pain, other than an everyday headache } \\
\hline On several days or fewer & 86 (59.3) \\
\hline On most days & 20 (13.8) \\
\hline Every day & $38(26.2)$ \\
\hline Not sure & $1(0.7)$ \\
\hline \multicolumn{2}{|l|}{ Loss of appetite } \\
\hline No & $59(40.7)$ \\
\hline Yes & $22(15.2)$ \\
\hline Sometimes & $26(17.9)$ \\
\hline Appetite is always small & $38(26.2)$ \\
\hline \multicolumn{2}{|l|}{ Weakness/tiredness/fatigue } \\
\hline On several days or fewer & $58(40.0)$ \\
\hline On most days & 20 (13.8) \\
\hline Every day & $67(46.2)$ \\
\hline \multicolumn{2}{|l|}{ Difficulty sleeping at night } \\
\hline On several days or fewer & $80(55.2)$ \\
\hline On most days & $16(11.0)$ \\
\hline Every day & 49 (33.8) \\
\hline \multicolumn{2}{|l|}{ Low mood } \\
\hline On several days or fewer & 108 (74.5) \\
\hline On most days & 15 (10.3) \\
\hline Every day & $22(15.2)$ \\
\hline \multicolumn{2}{|l|}{ Anxiety or panic } \\
\hline On several days or fewer & 128 (88.2) \\
\hline On most days & $8(5.5)$ \\
\hline Every day & $916.2]$ \\
\hline
\end{tabular}

agreed to an interview. There were no differences between participating and nonparticipating patients in age, sex, deprivation score (IMD), spirometry, or use of oral steroids. Participating patients were more likely to have been prescribed longterm oxygen therapy (67/163 versus 32/126; $\chi^{2}=7.785, P=0.005$ ), and were more likely to have been admitted to hospital for COPD (81/163 versus 48/126; $\chi^{2}=3.868, P=0.049$ )

One hundred and forty-five of the 163 patients interviewed met the inclusion criteria. Their characteristics are shown in Table 1. Most were in lower socioeconomic groups, most had low educational attainment, almost half lived alone, and one-fifth owned their own homes.

Reported symptoms and impact on daily living are shown in Tables 2 and 3. One- hundred and thirty-four (92\%) subjects described breathlessness as the problem causing the most difficulty. All 58 (40\%) subjects who reported pain other than a headache every day or most days were on prescribed analgesics. Of these, 26 had pains that they were unable to list in broad anatomical categories (for example, head, abdomen, or limb). There was a strong association between the ECOG score and reported breathlessness frequency $\left(\chi^{2}=\right.$ 60.4; degrees of freedom $[d f]=9 ; P<0.001$ ) and severity $\left(\chi^{2}=14.5 ; \mathrm{df}=3 ; \quad P=0.002\right)$. Eighty of 82 subjects with severe breathlessness described themselves as capable of limited self-care or as completely disabled (according to ECOG).

\section{Comorbidity}

Comorbidities were reported by 106 patients (73\%). The most common were ischaemic heart disease $(59,41 \%)$, arthritis $(33,23 \%)$, mental illness $(16,11 \%)$, diabetes mellitus $(11,8 \%)$, and stroke $(9,6 \%)$. There was no association between the number of comorbidities and the degree of severity of breathlessness or of impairment of lung function.

\section{Predictors of severe breathlessness}

Predictors of breathlessness were sought using the composite severe breathlessness variable. Eighty-two (57\%) subjects had severe breathlessness as defined by this composite severe breathlessness variable. There were significant correlations and associations between many combinations of variables and severe breathlessness, but no combination was sufficiently specific to be useful as a predictor of severe breathlessness in a clinical setting. Among the 63 patients in the study aged 75 years and younger, reporting of grade 5 breathlessness in the MRC Dyspnoea Scale had a specificity of $93.5 \%$ lvery few false positives) and a sensitivity of $52.7 \%$ lalmost $50 \%$ false negatives) in predicting severe breathlessness (by the composite variable).

\section{Drug use, use of services, and choice about place of care}

Reported drug use is shown in Table 4. Thirty per cent of subjects were on suboptimal treatment as defined in the GOLD guidelines. There was no association between reported drug use and symptoms, impact on daily living, respiratory-specific quality of life, rate of exacerbations, or use of services. The $67(46 \%)$ subjects who reported having attended pulmonary rehabilitation were more likely to have been 


\section{Table 3. Reported symptoms, quality of life, receipt of care, and performance status $(n=145$ )}

\begin{tabular}{|c|c|}
\hline COPD symptoms & $n(\%)$ \\
\hline \multicolumn{2}{|l|}{ MRC Dyspnoea Scale } \\
\hline 1-3: Breathlessness at worst resulting in slower walking than contemporaries & 12 [8.3] \\
\hline 4: Stops for breath after walking $100 \mathrm{~m}$ & $74(51.0)$ \\
\hline 5: Too breathless to leave the house, or breathless dressing and undressing & $59(40.7)$ \\
\hline \multicolumn{2}{|l|}{ Hospital Anxiety and Depression Scale (HADS) } \\
\hline High risk of anxiety: $H A D-A \geq 8^{b}$ & $51(35.2)$ \\
\hline High risk of depression: $H A D-D \geq 8^{c}$ & $63(43.4)$ \\
\hline \multicolumn{2}{|l|}{ Chronic COPD Questionnaire (CCQ) } \\
\hline Overall mean score (SD; range) d & $\begin{array}{c}3.0 \\
(1.1 ; 0.1-5.7)\end{array}$ \\
\hline \multicolumn{2}{|l|}{ Mobility } \\
\hline Able to get out of home & $66(45.5)$ \\
\hline Can get out with the help of portable oxygen & 15 (10.3) \\
\hline \multicolumn{2}{|l|}{ Difficulty with activities } \\
\hline Getting washed or bathing & 110 (75.8) \\
\hline Getting dressed & $87(60.0)$ \\
\hline Doing the housework & 131 (90.3) \\
\hline Preparing meals & $93(64.1)$ \\
\hline Getting around the home & $73(50.3)$ \\
\hline Looked after or receiving special help & $113(77.9)$ \\
\hline By person in own household & $65(44.8)$ \\
\hline By person in another household & $49(33.7)$ \\
\hline \multicolumn{2}{|l|}{ Eastern Cooperative Oncology Group (ECOG) performance status } \\
\hline Restricted but ambulatory with light work & $3(2.1)$ \\
\hline Ambulatory and capable of all self-care & 12 (8.3) \\
\hline Capable of limited self-care & $85(58.6)$ \\
\hline Completely disabled & $45(31.1)$ \\
\hline \multicolumn{2}{|c|}{ 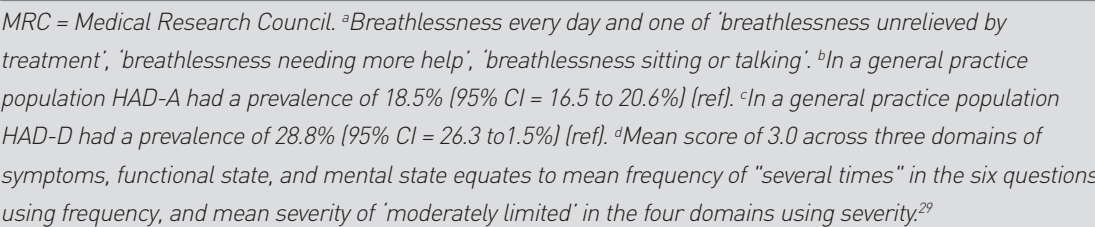 } \\
\hline
\end{tabular}

on optimal treatment lodds ratio [OR] 4.5; $95 \%$ confidence interval $[\mathrm{Cl}]=1.6$ to 12.3 ), more likely to have received oral steroids IOR 6; $95 \% \mathrm{Cl}=1.8$ to 19.7 ), and more likely to have had a nurse involved in their COPD care (OR 3.4; $95 \% \mathrm{Cl}=1.5$ to 7.4 ).

Forty-four (30\%) subjects reported regular contact with their GP 3-monthly or more often, with 97 (67\%) attending when needed. Eighty-seven (60\%) had regular contact with hospital. Attendance at the GP or at hospital was not associated with the degree of severity of breathlessness or of functional impairment.

One hundred and three (71\%) reported acute severe exacerbations within the previous 2 years, of whom 102 were admitted to hospital. Ninety-five (93\%) thought hospital admission was the right action, and one thought it was not right. If very unwell again, 86 (84\%). would have wanted to go back to hospital, but 13 (13\%) would not have wanted to go back because of dislike of the physical environment or the food, because of worry about infections such as meticillin-resistant Staphylococcus aureus (MRSA), or because they felt they could be equally well treated at home. None felt admission was futile, none expressed existential concerns about admission, and none wanted to risk treatment at home rather than face admission.

\section{Information needs}

Ninety-three (64\%) subjects reported that they had enough information about their current breathing problems, 102 (70\%) had been able to ask everything they wanted to about their chest trouble, and 99 (68\%) had been given the information in a way that was easy to understand. More information was wanted about how to control breathlessness by $78(54 \%)$, about what to expect with their chest trouble by $61(42 \%)$, about their medication by 84 (58\%), and about the future by 54 (37\%).

\section{Plans for future care and existential needs}

Future care was reported to have been considered by 31 (21\%) subjects, and 44 (30\%) made specific mention of plans that had been discussed. Twenty-seven (19\%) reported never having considered their future with COPD. Fifty-one (35\%) had given consideration to their future with COPD, including eight who planned to seek help from carers, eight who expected support by their families, 10 who planned to move house or move into a care or nursing home, four who had planned their funeral arrangements, two who had been referred to palliative care, two who had written a will, one who had received a 'do not resuscitate' order, and 15 who had made other individual comments. Explicit statements about preparation for death were not made but some patients were clearly approaching that position, as the following verbatim comment by a 65 -year-old married man with very severe breathlessness indicates:

'I have been told by the hospital that I have a short life expectancy and I was referred to end-of-life care. This made me a bit frightened, and made me think of death a lot. I try and shove it to the back of my mind. I feel like giving back nippy! [nippy is the popular term for non-invasive positive pressure ventilation - NIPPV]

Existential concerns, that is to say concerns about the meaning or value of life in relation to dying or possible death, were not expressed in the need for information about the future, in plans considered for the 


\section{Table 4. Reported use of respiratory drugs in patients with advanced COPD $(n=145)$}

\begin{tabular}{lc}
\hline Drug & $n(\%)$ \\
\hline Inhaled short acting beta-agonists & $137(94)$ \\
\hline Inhaled LABA supplied in separate inhaler & $18(13)$ \\
\hline Inhaled steroids supplied in separate inhaler & $29(20)$ \\
\hline Inhaled tiotropium & $91(63)$ \\
\hline Inhaled combined steroids and LABA & $88(61)$ \\
\hline Inhaled LABA and tiotropium & $61(42)$ \\
\hline Oral corticosteroids lincluding six held in reserve) & $32(22)$ \\
\hline Theophyllines & $9(6)$ \\
\hline Not on inhaled long-acting bronchodilators and inhaled steroids ${ }^{a}$ & $43(30)$ \\
\hline Oxygen & $59(41)$ \\
\hline Cylinder supply without concentrator & $14(10)$ \\
\hline Concentrator & $45(31)$ \\
\hline LABA = long-acting beta agonists. ${ }^{2}$ Long-acting bronchodilators means LABA or tiotropium.
\end{tabular}

future, in the reporting of action preferred in the event of a future exacerbation, or alongside open statements about the expectation of death from the disease, the making of wills, and anticipated dependence on relatives and carers.

\section{DISCUSSION}

\section{Summary}

In patients with advanced COPD recruited in primary care, palliative care needs were identified in the need for control of symptoms, principally breathlessness. Existential need was not reported and few talked about care needs in terms of 'end-oflife care', even among those who were aware of the likelihood of death from the disease and who had plans that included funeral arrangements or palliative care. It is possible that the most vulnerable patients for whom life with COPD had become unbearable did not participate. Despite the severity of their disease, $30 \%$ of the participants were on suboptimal treatment and more than half had never been referred to pulmonary rehabilitation. Thirty per cent of these advanced COPD sufferers had not been admitted to hospital in the previous 2 years. From these findings it is evident that not all of the most severely affected people with COPD were receiving active treatment.

\section{Strengths and limitations}

A high response rate (80\%) was obtained among the general practices invited to take part. The response rate among patients (61\%) was less satisfactory, but the finding that responders were at least as severely affected as non-responders and were no different in demographic characteristics and deprivation, was reassuring. More than
$98 \%$ of the UK population is registered with a GP, so it is unlikely that many subjects will have been excluded by recruiting from the lists of GPs. It is likely that some subjects with severe disease will have been missed due to underdiagnosis of COPD. ${ }^{34}$

The study included five frail older subjects with $\mathrm{FEV}_{1} /$ forced vital capacity (FVC) ratios that did not meet entry criteria because of their inability to sustain forced expiration due to breathlessness and frailty. Predicted values for subjects aged over 75 years are unreliable. ${ }^{17}$ Anxiety or panic and depression were reported at almost twice the rate observed in general practice populations..$^{35}$

Almost all of the subjects were white, despite being recruited in areas in which $26 \%$ of the population was black. The ethnicity of the subjects was similar to the ethnicity reported in a retrospective survey of COPD deaths in the same area 6 years previously. ${ }^{3}$ People in black ethnic groups are at least as likely to smoke as those in the population as a whole, although men in the UK born in the Caribbean have a low standardised mortality ratio of 0.7 for lower respiratory disease. ${ }^{36}$ The low representation of people of black ethnicity may reflect a combination of higher rates of underdiagnosis, a lower response, and a disproportionately low prevalence of severe COPD among older black people in south London. Across the whole sample, it is unlikely that many more severely affected people with diagnosed COPD were excluded or excluded themselves, since responders were at least as severely affected as nonresponders.

Some subjects in this study who had endof-life care concerns may not have been identified, either through a desire not to 
embarrass the researcher, or through a reticence to acknowledge their concerns. Limited declaration of end-of-life care concerns may also have resulted from the interview strategy, which was careful to avoid suggesting that patients were approaching the end of life, although endof-life concerns were addressed. Against this there is good evidence that end-of-life concerns were not overlooked. Almost all who had been admitted to hospital said they would want to be readmitted in the event of a further severe exacerbation. Subjects reported a wide range of symptoms, and $40 \%$ described themselves as profoundly incapacitated. Reports were in keeping with the level of lung function observed, and there was no reason to suspect that subjects were inhibited in reporting negative perceptions.

\section{Comparison with existing literature}

The findings of this study contest expectations that many people with advanced COPD in primary care settings wish to discuss care needs in terms of "endof-life care' .,6-9,37 The experience of palliative care specialists suggests that there are individuals with advanced COPD who have end-of-life care needs that are comparable to the needs of people with advanced cancer. In this study, people with advanced COPD in primary care seldom wished to frame their needs within an end-of-life care' context. This presents a challenge to the conceptualisation of the palliative care of chronic non-malignant disease within an end-of-life care strategy such as that promoted by the UK Department of Health. ${ }^{38}$

Palliative care needs in advanced COPD were formulated more in terms of the palliation of symptoms than in terms of the need for end-of-life care or advance care planning. For those with optimised COPD treatment, other routes for the treatment of their breathlessness need to be investigated. ${ }^{39}$ The best predictor of severe breathlessness in this group of subjects is category 5 in the MRC Dyspnoea Scale in patients aged 75 years and under. Routine use of the MRC Dyspnoea Scale is currently the subject of incentive payments in UK general practice. ${ }^{33}$ The identification of severe breathlessness is less reliable in individuals over the age of 75 years.

Most, if not all, of these patients were living with COPD rather than dying from it. Perhaps those for whom life or the participation in research seemed pointless or unbearable were among the $38 \%$ of patients who did not take part. Such patients cannot be identified easily through practice-based registers but their prevalence demands definition nonetheless.

\section{Implications for practice}

Limited reporting of end-of-life care needs in these subjects with advanced COPD recruited in primary care questions the current direction of palliative care service development for chronic non-malignant disease. Patients whose symptoms in advanced disease have increased slowly over years rather than weeks may experience continuing 'response shift' in their experience of their disease, and as a result may focus on the struggle to live rather than on end-of-life care. ${ }^{40}$ There is a striking contrast between these patients and those with severe breathlessness from advanced malignancy in whom breathlessness is usually associated with impending death in days or weeks. ${ }^{39,41}$ Severe breathlessness in advanced COPD is a daily reality. Many, if not most, of these patients know they may die from the disease, but death is not imminent in most, and is not specifically signalled by their breathlessness. In this context, the palliation of breathlessness in advanced COPD appears more important for patients than consideration of end-of-life care. 


\section{REFERENCES}

1. Gore JM, Brophy CJ, Greenstone MA. How well do we care for patients with end stage chronic obstructive pulmonary disease (COPD)? A comparison of palliative care and quality of life in COPD and lung cancer. Thorax 2000; 55(12): 1000-1006.

2. Edmonds P, Karlsen S, Khan S, Addington-Hall J. A comparison of the palliative care needs of patients dying from chronic respiratory diseases and lung cancer. Palliat Med 2001; 15(4): 287-295.

3. Elkington $\mathrm{H}$, White $\mathrm{P}$, Addington-Hall J, et al. The healthcare needs of chronic obstructive pulmonary disease patients in the last year of life. Palliat Med 2005; 19(6): 485-491.

4. Skilbeck J, Mott L, Page $\mathrm{H}$, et al. Palliative care in chronic obstructive airways disease: a needs assessment. Palliat Med 1998; 12(4): 245-254.

5. Seamark DA, Blake SD, Seamark CJ, Halpin DM. Living with severe chronic obstructive pulmonary disease (COPD): perceptions of patients and their carers. An interpretative phenomenological analysis. Palliat Med 2004; 18(7): 619-625.

6. Murray SA, Pinnock H, Sheikh A. Palliative care for people with COPD: we need to meet the challenge. Prim Care Respir J 2006; 15(6): 362-364.

7. Rocker GM, Sinuff T, Horton R, Hernandez P. Advanced chronic obstructive pulmonary disease: innovative approaches to palliation. J Palliat Med 2007; 10(3): 783-797.

8. Seamark DA, Seamark CJ, Halpin DM. Palliative care in chronic obstructive pulmonary disease: a review for clinicians. J R Soc Med 2007; 100(5): 225-233.

9. Curtis JR. Palliative and end-of-life care for patients with severe COPD. Eur Respir J 2008; 32(3): 796-803.

10. Connors AF Jr, Dawson NV, Thomas C, et al. Outcomes following acute exacerbation of severe chronic obstructive lung disease. The SUPPORT investigators (Study to Understand Prognoses and Preferences for Outcomes and Risks of Treatments). Am J Respir Crit Care Med 1996; 154(4 part 1): 959-967.

11. Almagro $P$, Calbo E, Ochoa de EA, et al. Mortality after hospitalization for COPD. Chest 2002; 121(5): 1441-1448.

12. Celli BR, Cote CG, Marin JM, et al. The body-mass index, airflow obstruction, dyspnea, and exercise capacity index in chronic obstructive pulmonary disease. N Engl J Med 2004; 350(10): 1005-1012.

13. World Health Organization. WHO definition of palliative care. Geneva: World Health Organization, 2008.

14. Shipman C, Gysels M, White $P$, et al. Improving generalist end of life care: national consultation with practitioners, commissioners, academics, and service user groups. BMJ 2008; 337: a1720.

15. Higginson IJ, Hart S, Koffman J, et al. Needs assessments in palliative care: an appraisal of definitions and approaches used. J Pain Symptom Manage 2007; 33(5): 500-505.

16. Quanjer PH, Tammeling GJ, Cotes JE, et al. Lung volumes and forced ventilatory flows. Report Working Party Standardization of Lung Function Tests European-Community for Steel and Coal. Official Statement of the European Respiratory Society. Eur Respir J 1993; 6: 5-40.

17. Falaschetti E, Laiho J, Primatesta P, Purdon S. Prediction equations for normal and low lung function from the Health Survey for England. Eur Respir J 2004; 23(3): 456-463

18. Miller MR, Pedersen OF, Dirksen A. A new staging strategy for chronic obstructive pulmonary disease. Int J Chron Obstruct Pulmon Dis 2007; 2(4): 657-663.

19. Office for National Statistics. Neighbourhood statistics. Titchfield: Census Customer Services, 2008.
20. Shipman C, White S, White PT. Access to services in advanced COPD: factors that influence contact with general practice services. Prim Care Respir J 2009; 18(4): 273-278.

21. Ritchie J, Spencer L. Qualitative data analysis for applied policy research. In: Bryman A, Burgess RG (eds). Analyzing qualitative data. London: Routledge, 1994.

22. Bestall JC, Paul EA, Garrod R, et al. Usefulness of the Medical Research Council (MRC) dyspnoea scale as a measure of disability in patients with chronic obstructive pulmonary disease. Thorax 1999; 54(7): 581-586.

23. Torrance N, Smith BH, Bennett MI, Lee AJ. The epidemiology of chronic pain of predominantly neuropathic origin. Results from a general population survey. J Pain 2006; 7(4): 281-289.

24. Oken MM, Creech RH, Tormey DC, et al. Toxicity and response criteria of the Eastern Cooperative Oncology Group. Am J Clin Oncol 1982; 5(6): 649-655.

25. Chochinov HM, Hack T, McClement S, et al. Dignity in the terminally ill: a developing empirical model. Soc Sci Med 2002; 54(3): 433-443.

26. Bjelland I, Dahl AA, Haug TT, Neckelmann D. The validity of the Hospital Anxiety and Depression Scale. An updated literature review. J Psychosom Res 2002; 52(2): 69-77.

27. Van Der MT, Willemse BW, Schokker S, et al. Development, validity and responsiveness of the Clinical COPD Questionnaire. Health Qual Life Outcomes 2003; 1(1): 13

28. Cohen SR, Mount BM, Tomas JJ, Mount LF. Existential well-being is an important determinant of quality of life. Evidence from the McGill Quality of Life Questionnaire. Cancer 1996; 77(3): 576-586.

29. Pang SM, Tse CY, Chan KS, et al. An empirical analysis of the decisionmaking of limiting life-sustaining treatment for patients with advanced chronic obstructive pulmonary disease in Hong Kong, China. J Crit Care 2004: 19(3): 135-144.

30. Miller MR, Hankinson J, Brusasco V, et al. Standardisation of spirometry. Eur Respir J 2005; 26(2): 319-338.

31. Noble M, McLennon D, Wilkinson K, et al. The English Indices of Deprivation 2007. London: Department for Communities and Local Government, 2008.

32. Rabe KF, Hurd S, Anzueto A, et al. Global strategy for the diagnosis, management, and prevention of chronic obstructive pulmonary disease: GOLD executive summary. Am J Respir Crit Care Med 2007; 176(6): 532-555.

33. NHS. The Information Centre for Health and Social Care. The Quality and Outcomes Framework (QOF) 2007/08. Leeds: NHS Information Centre, 2008.

34. Bednarek M, Gorecka D, Wielgomas J, et al. Smokers with airway obstruction are more likely to quit smoking. Thorax 2006; 61(10): 869-873.

35. Olsson I, Mykletun A, Dahl AA. The Hospital Anxiety and Depression Rating Scale: a cross-sectional study of psychometrics and case finding abilities in general practice. BMC Psychiatry 2005; 5: 46.

36. Lung and Asthma Information Agency. Ethnic variations in lower respiratory disease. London: St George's Hospital Medical School, 2001.

37. Edmonds P, Karlsen S, Khan S, Addington-Hall J. A comparison of the palliative care needs of patients dying from chronic respiratory diseases and lung cancer. Palliat Med 2001; 15(4): 287-295.

38. Department of Health. End of Life Care Strategy - promoting high quality care for all adults at the end of life. London: Department of Health, 2008.

39. Booth S, Moosavi SH, Higginson IJ. The etiology and management of intractable breathlessness in patients with advanced cancer: a systematic review of pharmacological therapy. Nat Clin Pract Oncol 2008; 5(2): 90-100.

40. Wilson IB. Clinical understanding and clinical implications of response shift. Soc Sci Med 1999; 48(11): 1577-1588.

41. Reuben DB, Mor V. Dyspnea in terminally ill cancer patients. Chest 1986; 89(2): 234-236. 